\title{
Combining Individual and Group Counselling Sessions in a Smoking Cessation Intervention
}

\author{
Vasiliki Zisi, Stamatia Gratsani, Despoina Leontari, Yannis Theodorakis \\ Faculty of Physical Education and Sport Science, University of Thessaly, Trikala, Greece \\ Email: vzisi@pe.uth.gr
}

How to cite this paper: Zisi, V., Gratsani, S., Leontari, D., \& Theodorakis, Y. (2016). Combining Individual and Group Counselling Sessions in a Smoking Cessation Intervention. Psychology, 7, 1766-1784. http://dx.doi.org/10.4236/psych.2016.714165

Received: October 24, 2016

Accepted: November 26, 2016

Published: November 29, 2016

Copyright $\odot 2016$ by authors and Scientific Research Publishing Inc. This work is licensed under the Creative Commons Attribution International License (CC BY 4.0).

http://creativecommons.org/licenses/by/4.0/ (c) (i) Open Access

\begin{abstract}
The present study aimed to investigate if and how the inclusion of group counselling sessions in an individual counselling intervention program affects the participants' effort to give up smoking and adopt a healthier lifestyle by increasing their physical activity. It was also aimed to identify specific techniques, characteristics and qualities of group sessions and also the dynamics of the certain closed but heterogeneous group (all the members started and finished the group meetings together, however they were at a different level of behaviour change). The participants were 5 men and 3 women aged 39 to 47 years. The intervention included 12 individual and 3 group sessions, while the follow up was set to 6 months after the last individual meeting. Individual counselling was person-centered and based on motivational interviewing. Group counselling aimed to communication, acceptance, sharing experiences and feelings among the group members about their common goal. A semi-structured interview was used to evaluate the effectiveness of the program. According to the results, the inclusion of group sessions contributed positively to the process of smoking cessation. The participants reported that the sense of not being alone and the existence of a safe environment, which was the frame of the team, in which they could express themselves and share knowledge, experiences and emotions, to be very helpful. The different progress levels of the participants seemed to be really helpful for them. Regarding the success rate, $87.5 \%$ of the participants ( 7 out of 8 ) achieved their goal at the end of the program, while in the follow up there was only one relapse and the effectiveness of the program reached $75 \%$.
\end{abstract}

\section{Keywords}

Smoking Cessation, Group Counselling, Physical Activity, Transtheoretical Model, Adapted Motivational Interviewing (AMI) 


\section{Introduction}

Group interventions have been used in the last decades as a technique to address the addiction to nicotine, alcohol and other toxic substances. Group counselling is based on the mutual commitment of the team members, who face the same problem and the same difficulties, and the support they provide to each other. During group counselling sessions, the team members have the opportunity to exchange their experiences and share their feelings (Nystul, 1993; Yalom, 2006).

Group counselling programs aiming to smoking cessation have been proved to have higher rates of success compared to the self-help smoking cessation programs (Stead \& Lancaster, 2005, 2009). Research also proved a greater efficacy of the groups compared to the self-help programs and less intensive interventions; there were however, no satisfactory evidence of their effectiveness on smoking cessation as opposed to intensive individual interventions (Moller \& Tonnesen, 1999) or short-term individual interventions (Camarelles et al., 2002).

Group counselling doesn't seem to be effective in all cases. The investigation of Ramos et al. (2010), which was designed to compare the effectiveness of individual and group interventions for smoking cessation in primary care showed that there were no statistically significant differences between the results of individual and group interventions. Weiss et al. (2004), concluding their study, which was designed to compare the group treatment with other forms of treatment regarding substance use by saying that no type of therapy (group or individual) has not been proved to be more effective than others.

The studies mentioned above, explore the effects of both individual and group counselling programs in smoking cessation, by comparing these two session types. It is not known however, a study that focuses on their combination, a counselling program for smoking cessation, which includes both individual and group sessions. The present study was conducted taking into account that such a program might have an important contribution to the design and implementation of more effective smoking cessation interventions. The aim of the study is to bring out some key points of the individuals' effort to give up smoking and increase their physical activity patterns, in order to adopt a healthier lifestyle. More specifically, the study aimed to investigate the specific techniques, characteristics and qualities of group sessions that help the consulting, and also to find out how group dynamics affect the above procedure.

The group counselling used in this study followed an alternative to the classical group counselling pattern. The key differentiation was that the participants in the certain intervention program were in different stages of behaviour change, regarding smoking cessation. In a typical group counselling program, the participants usually are at a similar starting point; they work with a specific material and specific goals in each session, and they are all at the same stage. The participants in the current intervention program formed a closed group, which means that they all started together and finished together the group sessions, however they were in a different stage of behaviour change, as they were following the same time an individual counselling program for smoking 
cessation. Some of them were making the first steps toward the preparation of smoking cessation; some of them have just quit smoking, while others were trying to stabilize their smoke-free behaviour.

The counselling technique used in the present study was based on the Theory of Motivational Interviewing (Miller \& Rollnick, 1991). It is going about a person-cantered counselling aiming to increase motivation, enhance the individual's motives to change, enhance self-efficacy and provide guidance, so that to understand the behaviour without any pressure from the counselor'spart for a change. Motivation to change is elicited from within the individual and not imposed from outside (Miller \& Rollnick, 2002). It is a way of communicating and being with people, a style of counselling and psychotherapy, not a set of techniques. The counselorshall respect the autonomy and freedom of choice of the individual, which has a prominent role in the whole process (Rollnick \& Miller, 1995; Miller \& Rollnick, 2002).

\section{Methods}

\subsection{Study Criteria and Recruitment}

The study was carried out in Trikala, a town in central Greece. An advertisement in local newspapers invited participants who were interested to give up smoking. A specific mobile phone number was dedicated to the communication with those interested in the smoking cessation counselling program and later with the participants. During the first contact, they were orally informed by one of the researchers (3rd author) about the aim of the research, the procedures and the number of visits needed for the completion of the intervention program. They also received a consent form, where they declared, that they are willing to give up or reduce smoking and were informed that questionnaires and transcripts would be anonymized, treated confidentially and that they were free to withdraw at any point during the study, if they so wished.

The group sessions started when there were 8 persons that signed the informed consent agreeing to participate in both individual and group counselling sessions. They were five men and three women and their ages ranged from 39 to 47 years ( $M=41.6$ years). They all were heavy smokers ( $>20$ cigarettes per day) and they didn't use any medication or nicotine substitutes in their effort to give up or reduce smoking. Four of the participants declared that they want to give up smoking and four of the participants declared that they want to reduce smoking below 10 cigarettes per day. Ethical approval for the study was obtained by the Ethics Committee of the department of physical education and sport science, University of Thessaly, Greece (1-1/20-06-2012).

\subsection{Intervention}

The intervention in total consisted of 12 individual and 3 group sessions. The frequency of the individual sessions was once per week and their duration was one hour. Throughout the individual counselling schedule, there were 3 group sessions, with a 6 weeks interval, of one hour duration. There was a six months follow up including 3 individual, one hour counselling sessions. 
a) Phone calls were used in parallel with the counselling sessions and they were made on a weekly basis during the intervention phase and on a monthly base during the follow up. The aim of these phone calls during the intervention phase was to help the participants remain in their goals. During the follow up, the phone calls aimed not only to collect information about the participant's smoking behaviour, but also to provide support and help on whatever the individual needed to sustain the behaviour change and avoid relapsing.

b) Individual counselling was person-centred and based on the theory of Motivational Interviewing (Miller \&Rollnick, 1991). In each individual counselling session, certain objectives, which the participant should accomplish until the next meeting, were set and discussed. The objectives focused mainly on issues of reducing the number of cigarettes smoked, exercise and diet, stress management and time organization. The material used during individual sessions originated from the manual "No more smoking! It's time for exercise" (Hassandra et al., 2012).

c) Group counselling aimed in communication, acceptance, sharing experiences and feelings among the group members about their common goal of smoking cessation. The certain group was closed, that is all the members started and finished the group meetings together. The techniques used in group meetings were brainstorming, role playing, discussion, completing booklets and questionnaires. Visualization and relaxation techniques were also used at some meetings. Each meeting was planned to provoke discussion and exchange of experiences on a certain topic. The contents of each group meeting are outlined on Table 1 and described in detail below:

1) At the first group meeting, after the group members introduced themselves, they got introduced to group counselling. They were asked to present their views on what they thought might be the group meeting process that will follow. They were allowed to express their feelings about the certain process and also the benefits they

Table 1. Outline of the group sessions contents.

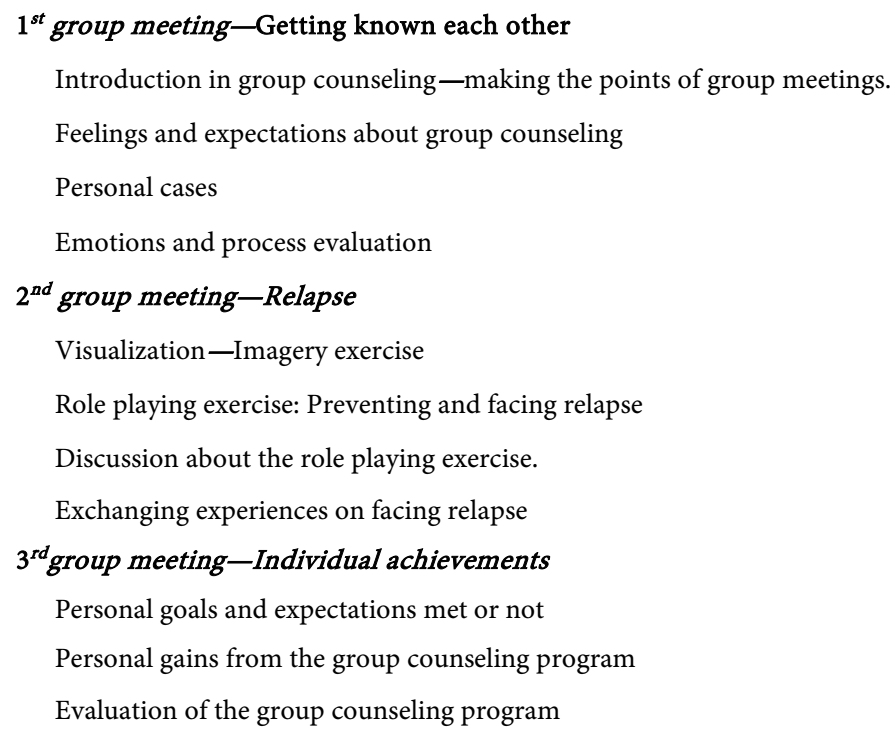


were expecting from it. Next, using various techniques such as brainstorming and filling anonymous forms, there was a discussion about the smoking history of each group member, their present situation, the pros and cons of smoking cessation, the difficulties they were facing, and about whatever was helpful during a past smoking cessation effort. Finally, it was discussed their feelings and perceived benefits about the certain group meeting.

2) The goal of the second group meeting was the discussion of relapse, an issue that has been raised from the first group meeting. A visualization exercise was used to mobilize the participants to discuss and exchange opinions on the scenario of a role playing game. The topic of this game aimed to the prevention of a relapse and the way they should phase a relapse. The game was followed by a discussion with the whole team commenting on their impressions, thoughts and reflections during this process. The discussion continued and the team members exchanged experiences, shared feelings, collected ideas on addressing relapse and difficult moments. The discussion intended to help the participants to increase their self-confidence, be prepared for potentially difficult moments in the future and feel safer regarding their pool of techniques they might have to use at such a moment.

3) The third and last group meeting was a discussion and commentary on the individual goals achieved and the smoking cessation stage of the participants. The individual perceived benefits as opposed to the individual expectations at the beginning of the program were discussed. This was followed by discussion and evaluation of the group counselling experience, exchanging views on what was mostly helpful and making suggestions on what should be included or excluded from this type of counselling for smoking cessation, in the future. The session was closed by having the participants to express their feelings and emotions on the whole group meetings process.

\subsection{Follow up}

After the completion of the intervention phase of the smoking cessation program 3 follow-ups were held individually. There were also frequent telephone calls on a weekly basis for 6 months. The purpose of the follow-ups was to obtain information about the situation of the participant, to provide support and help in anything needed and the ultimate goal was the consolidation of change and the relapse prevention.

\subsection{Instruments}

At the beginning and at the end of the intervention, a semi-structured, individual interview was used, lasting about one hour. The pre-intervention interview was used to collect demographic data, smoking and exercise history, family smoking history and other necessary information to create the profile of the participant. The post-intervention was used to assess the effectiveness of individual counselling and group sessions, and also in order to shape the actions and technics that helped or made it difficult for the participants during the intervention process. 


\subsection{Data Analysis}

Interviews with each participant were conducted in person, were audiotaped and transcribed. Transcribed data were analyzed using the content analysis. To organize the data, the program Qualitative Software Package N Vivo, ver. 7 was used. The questions from the interview were used as first order of the classification of questions. The second order of classification was created according to the answers in the questions.

\section{Results and Discussion}

At first, it is important to mention that $50 \%$ of the participants $(n=4)$ achieved the goal of smoking cessation and remained non-smokers until the final follow up. A significant proportion of $37.5 \%(n=3)$ achieved a significant decrease, which was retained until the final follow up. Only one person (12.5\%), despite achieving a significant reduction during the course of the program, returned to his/her initial smoking status at the follow up. In Figure 1 the above results are presented classified according to the participants' intention to change their smoking habits, as it was recorded in the pre-intervention interview. It is clear that 3 of the participants that joined the program with the decision to stop smoking, achieved their goal. The 3 participants that joined the program because they wanted to reduce smoking, also achieved their goal, and at the follow up one of them has gone further, by quitting smoking. The success rate of the program was thus, $75 \%$. It is also worth mentioning that at the follow up there was only one relapse to the former smoking status.

The results from the content analysis, regarding the questions about the group counselling sessions are presented below

1) How helpful were the group sessions?

As shown in Table 2, most of the participants (5 out of 7 people) agreed that the group sessions were very helpful. The phrase driving force is characteristic of the help

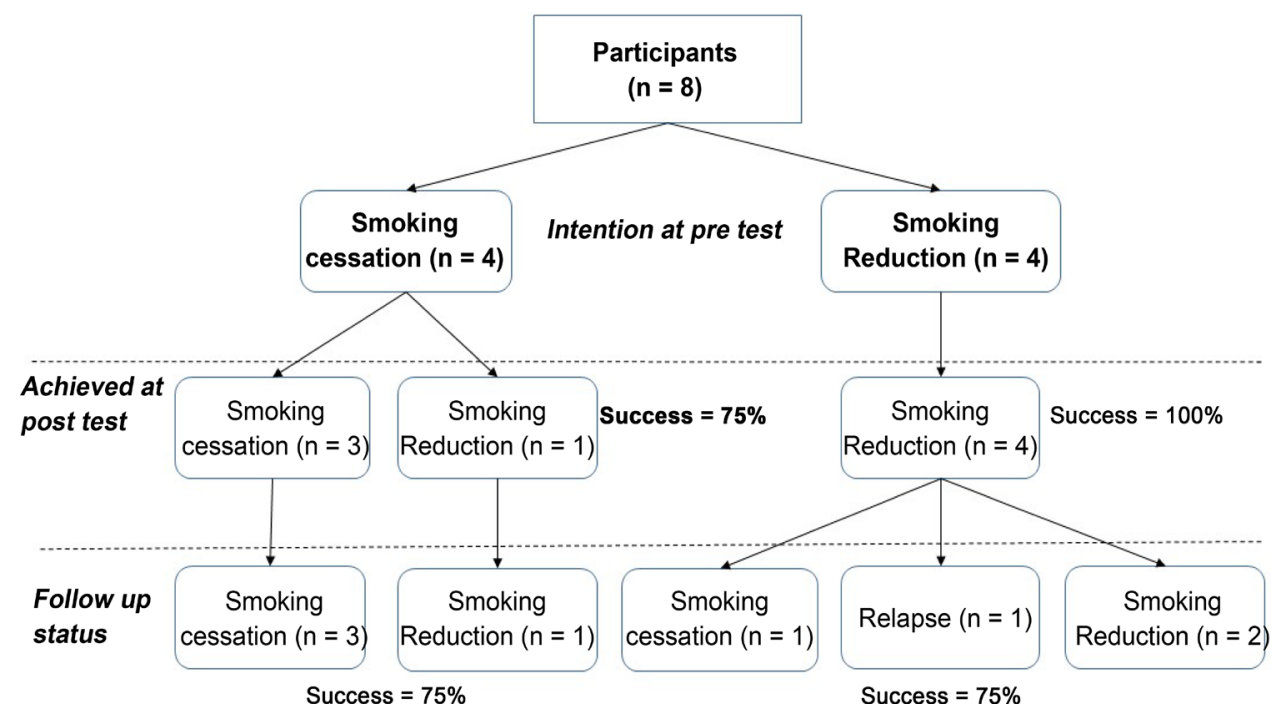

Figure 1. Smoking cessation achievement according to the participants' intention in the beginning of the intervention. 
Table 2. Results for the question how helpful were the group sessions?

\begin{tabular}{|c|c|}
\hline $2^{\text {nd }}$ order & Quotations \\
\hline Very much $(n=5)$ & The group sessions helped me very much. The group has been a driving force for me. \\
\hline Enough $(\mathrm{n}=2)$ & $\begin{array}{l}\text { The group sessions helped me enough. I saw and heard opinions, feelings and } \\
\text { thoughts from other people who are in the smoking cessation effort. I felt nice and I } \\
\text { was able to accomplish my goal. I was charmed and satisfied with the idea that I also } \\
\text { may help out and convince other people succeed. }\end{array}$ \\
\hline Not at all $(\mathrm{n}=1)$ & $\begin{array}{l}\text { I did not like the whole process. I think I was not helped at all from group sessions. I } \\
\text { participated in only one of the group sessions. I do not like to speak in front of others } \\
\text { for my own issues. Maybe it was a defense, because I saw that I have done the fewer } \\
\text { steps than all the others. }\end{array}$ \\
\hline
\end{tabular}

that the participants perceived they receive and indicates the dynamic of the group in a smoking cessation effort. There are also similar results in other studies, supporting that the participation of an individual in a group counselling program for smoking cessation, seems to increase the chances of cessation (Stead \&Lancaster, 2009). However, although several studies agree that higher smoking cessation rates were achieved in group interventions rather than individual, no statistically significant differences have been reported (Ramos et al., 2010).

Two more participants answered positively (enough helpful) about the group sessions. Their attitude was based not only on opinions but also on others' emotions and thoughts that they came up to during the group sessions. Their answers put an emphasis on their feelings. According to Huang (2005), adults need something more than information or treatment, they need help, technical, emotional support. Given the proper techniques, smokers may control their smoking behaviour.

There was only one negative answer from an individual that admitted having a rather defensive behaviour, because he/she was not feeling so confident with his/her progress.

2) Which group activities carried out during the group sessions helped you more?

The questions in this category were made to identify those activities that helped most participants during group sessions to demonstrate the most effective activities, which should be included in group sessions.

As shown in Table 3, most of the participants $(n=6)$ referred to the exchange of views and experience as the main activity that helped them most, especially on finding ways to face the difficulties. Through the exchange of views and experiences, each member introduces to the group the stress and experience acquired in his life (Douglas, 2000). The different stage of behaviour change reached by each participant, the different experience in smoking cessation attempt, fed this exchange of views and experiences, which for most of the participants seemed particularly helpful. Moreover, according to the psychodynamic theory (Glassman, 1995), the purpose of individuals is the relief of tension that creates anxiety and distress, which in the case of this research comes from the nicotine dependence. Reducing anxiety with some form of transfer, promotion or imagination can be easily seen and is available to the group due to the physical proximity of members, interaction and emotional involvement in group activities. 
Table 3. Results for the question which group activities, carried out during the group sessions helped you more?

\begin{tabular}{|c|c|}
\hline $2^{\text {nd }}$ order & Quotations \\
\hline $\begin{array}{l}\text { All exercises-activities } \\
\qquad(\mathrm{n}=4)\end{array}$ & $\begin{array}{l}\text { All the exercises gave us the opportunity for more interaction and } \\
\text { discussion with the other members, something that strengthened the } \\
\text { team building. }\end{array}$ \\
\hline $\begin{array}{l}\text { The visualization exercises } \\
\qquad(\mathrm{n}=1)\end{array}$ & $\begin{array}{l}\text { They helped us to imagine how it may be some future situations and } \\
\text { how we might address them }\end{array}$ \\
\hline $\begin{array}{l}\text { Role playing } \\
\qquad(\mathrm{n}=1)\end{array}$ & $\begin{array}{l}\text { It was especially helpful that we entered into different roles and could } \\
\text { understand thus the feelings of the others and also we could see things } \\
\text { from a different perspective, which might help us. }\end{array}$ \\
\hline $\begin{array}{l}\text { The advice from other members } \\
\qquad(\mathrm{n}=2)\end{array}$ & $\begin{array}{l}\text { I applied all the advices of the other members to see what suits me and } \\
\text { what not, and so I discovered new tricks. }\end{array}$ \\
\hline $\begin{array}{l}\text { The advice from the counselor } \\
\qquad(\mathrm{n}=2)\end{array}$ & The advices from the counselor are the only things I implemented \\
\hline $\begin{array}{l}\text { Exchanging views-discussion } \\
\qquad(\mathrm{n}=6)\end{array}$ & $\begin{array}{l}\text { Exchanging views with the other members of the team were very } \\
\text { helpful. I heard things that I had not ever thought, mainly about how } \\
\text { to confront the difficulties }\end{array}$ \\
\hline
\end{tabular}

The interaction is a key feature among the members of a group and it is something that brings understanding, disseminates information, improves and enhances opinions, facilitates the achievements of the team. Of course there is the view that this interaction between the group does not necessarily have any effect on the outcome (Stead \& Lancaster, 2005), but in the certain question - which group activities, carried out during the group sessions helped you more? - the second most common answer $(n=4)$ was that all the activities were helpful, since they were providing opportunities for interaction and discussion. These answers, underline the role of interaction among the members of the certain group. The participants could exchange knowledge, experiences and tips with each other. This gave them the opportunity to "get" things by their counterparts. They could see different situations, take ideas and make comparisons. The positive feelings of those who have achieved their goals, mobilized the others to also try to succeed their objectives and experience similar feelings.

The knowledge exchanged among the participants, appear to constitute a key energy source for the group, since the strengthening of existing views and beliefs in combination with the new knowledge, provided a yardstick for their behaviour. By exchanging knowledge and experience, the team members come to an imitation process. Apart from the answers to comply with the consultant's advice only $(n=2)$, there were other answers $(n=2)$ showing the desire and perhaps curiosity of some team members to follow the strategies of some other members. It seems that the participants are able to emulate, beyond the therapist, some features of other members of the group (Borgers, 1983). Team members learn by observing how each member handles its problems, capture some behaviours from others and reproduce them, especially when, in this way, they gain the acceptance of the group (Douglas, 2000). 
Participants report that visualization exercises $(n=1)$ and role playing $(n=1)$ strengthened further the tying they felt. Moreover they report that teamwork helped them to be more motivated, committed, determined and face more seriously all this effort. The group is a laboratory for experimentation and a safe environment to try new behaviours. After the tests the members will decide what behaviours they want to change. The role playing is usually an effective way for the members of a group to develop new skills in human relationships beyond those that they usually apply to situations outside group (Tudor, 1999), as they have the possibility to experiment with new ways of expression (Winnicott, 1971).

3) Which characteristics of the group sessions helped the participants?

The purpose of this set of questions was to see what features of the group meetings helped more the participants and how. As shown in Table 4, the amount of information recorded from the interviews is quite large and created thus not only the 2 nd but also a 3 rd row of categorization. The answers of the participants were classified into 4 categories concerning: a) the structure of the group, b) the content of the group meetings, c) the functioning of the group meetings in the individual effort of quitting smoking, d) the techniques developed by the participants based on elements they gathered from the individual sessions.

\section{a) Structure}

The structure of the group appeared to be very effective since the majority of the participants reported that the composition of the group helped them a lot $(n=5)$. The different stage of each participant's behaviour change did not reduce the effectiveness of the team, on the contrary, as the participants mentioned, it resulted on the impression that one is pushing the other. Apparently, this was helped the good cohesion of the group. Besides, 75\% of the participants reported that the cohesion of their team helped them to feel more committed and motivated to continue their effort $(n=6)$. The cohesion-consistency seems to be for the groups what is relation for the individual therapy. It has been shown that the members of a cohesive group, in contrast to the members of an inconsistent group, will try harder to influence the rest of the group (Goldstein, Heller, \& Sechrest, 1966), will be more willing to listen to others and approve them more, participate more willingly in the meetings (Rasmussen \& Zander, 1954), will be more self-revealed (Kirschner, Dies, \& Brown, 1978) and in generally will experience greater social contact with other members, they will feel more that the whole process of the group therapy belongs to them (Yalom, 2006).

All these characteristics of the high consistency groups may contribute to the development of good relations and effective interaction, something reported by the group members of this study $(n=6)$. Actually, in the high consistency groups, in contrast to the low consistency groups, there is more positive interaction and in a greater degree, greater satisfaction and greater effectiveness in achieving the objectives that has been set (Shaw, 1974).

\section{b) Content}

Regarding the content of the group sessions, participants reported that sharing ex- 
Table 4. Results for the questionWhich characteristics of the group sessions helped the participants?

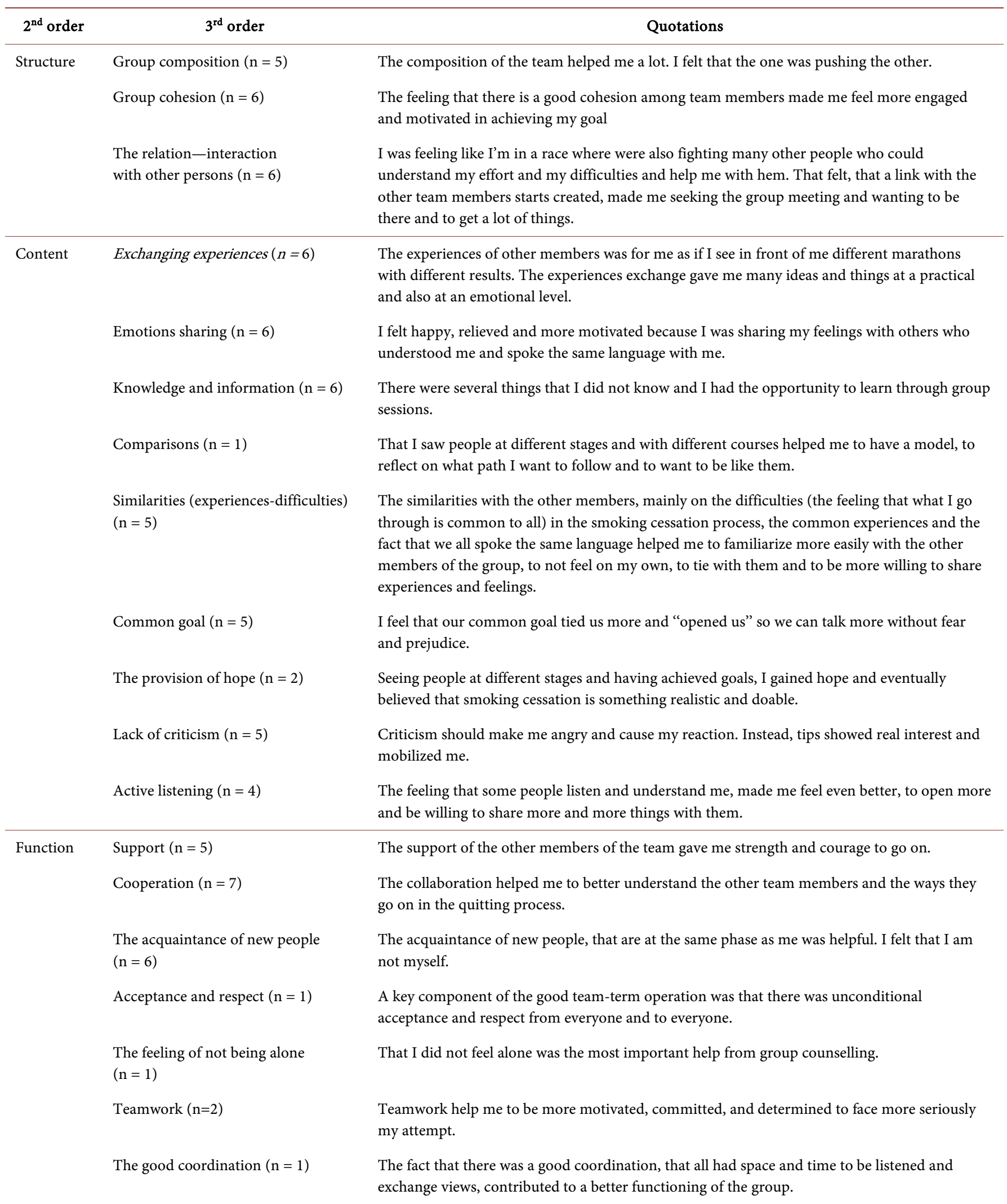




\section{Continued}

Techniques Commitment $(\mathrm{n}=5)$

Providing and receiving assistance $(\mathrm{n}=5)$

Providing and receiving reinforcement $(\mathrm{n}=5)$

Feedback $(\mathrm{n}=5)$
Commitment helped me the most. I was thinking that I have been committed to so many people and how it will be to come someday and tell them that I started smoking. The group for me was the "grip" so as not to give in to the temptation, and the reference point, where I would be accountable in case of relapse.
Particularly important was the help from the other members, through advices and ideas that I never had in my mind. I am charmed and satisfied with the idea that I can help and persuade other people to succeed.

The positive reinforcement I received throughout the program both of the other team members and the consultant was something that particularly cheered me up, because I saw that my goal, that was quite difficult, and my effort were recognized and this strengthened me to continue. I have achieved the goal of quitting but the effort is not over yet. Now I fight daily for the goal of preservation. Thus, in my turn and seeing how important is strengthening, I also tried to reinforce the other group members respectively.

\begin{tabular}{|c|c|c|}
\hline & Feedback $(\mathrm{n}=5)$ & $\begin{array}{l}\text { The feedback from the other members of my team have strengthened my confidence when I felt } \\
\text { that I am not making important steps and helped me thus to keep trying. It operated as a } \\
\text { driving force. }\end{array}$ \\
\hline $\begin{array}{l}\text { Techniques } \\
\text { (continued) }\end{array}$ & Intrinsic motivation $(n=5)$ & $\begin{array}{l}\text { The fact that I was internally motivated was the basis on which all the rest were built. Because } \\
\text { of this I managed to work within the team and got things. I think if I was not motivated most } \\
\text { likely the group should not help me at all. }\end{array}$ \\
\hline
\end{tabular}

periences helped them the most $(n=6)$, at both practical and emotional level. The characteristic response: it was for me as if I see in front of me different marathons with different results, indicates the acceptance of diversity in the group. Both the acceptance and the development of diversification are principles of motivational interviewing (Miller \& Rollnick, 1991, 2002), on which the counselling during individual sessions was based. It seems that this technique influenced the participants' perception and thinking, in a way to make comparisons, to search for information not only knowledge but also conditions that may resemble theirs.

It is even very likely that the consulted mimics the behaviour of the consultant during the individual sessions and as it was identified by the majority of participants, they become active listeners $(n=4)$ but without criticizing $(n=5)$. This lack of critical attitude and the existing willing for assistance was something that mobilized everyone to engage even more in the process of group sessions and did not repel them. The counselling process might be beneficial since it implies and conveys mutual caring and interest and does not only focus on the content (Yalom, 2006). As the participants in this research said, the advisor showed real interest and mobilized them.

The advice given by the other team members, and even a team with good cohesion, was nothing more than knowledge and information provided in good faith. Most of the participants admitted that through the group sessions they learned many new things ( $\mathrm{n}$ 
=6). Through this flow of information given in the form of advice, participants had the opportunity to realize their common goal, something admitted by the majority of the participants $(n=5)$. Their common goal was the key point that tied them more and made them participate and speak out without fear and prejudice, to talk about themselves, about their experiences and their feelings.

The feelings sharing, as most of the participants said $(n=6)$, made them feel that they are not alone and that there are other people who put the same effort and with whom they feel they speak the same language. All this made them feel very relieved after seeing that their experience is shared and understood by others. The expression of emotions has proved to be particularly helpful because it releases energy and makes the person feel more free (Yalom, 1985). The expression of emotions and the exchange of experience are directly related to the phenomenon of contamination to which Douglas (2000) makes reference. As in the case of an infectious disease the bacteria pass from one person to another through some kind of contact, so is the case in the groups, most notably in emotions like anger, distrust, hatred, love, trust, warmth but also acts or participation in acts that people would never tried by themselves, something that many times leads them to discover opportunities that they could not even imagine (Douglas, 2000).

The sense of freedom to share feelings was further facilitated by the recognition of the similarities that existed between the participants. Like most of the participants ( $\mathrm{n}=$ 5) said, the common experiences and the difficulties in quitting process, helped them understand and be tied with the other members and be more commited. Universality is considered one of the key factors affecting the process in groups (Woody, Hansen, \& Rosberg, 1989). According to Mac Kenzie and Livesley (1984) the awareness and recognition that other people have similar problems and experiences are the primary mechanism for the development of commitment in a team. As Yalom (1985) argues, many people initially entering a group have the disturbing thought that they are unique in their misery, that they are the only ones who have problems, since in everyday life they are not easily given the chance to learn that other people have similar feelings and experiences, and to share their problems with others and finally being accepted by them. Within the groups, the rejection of the feeling of uniqueness that the consulted is perhaps experiencing, is a great source of relief. This is the first step to reduce feelings of isolation and diversity.

In the certain group, where members were at a different stage of change of the problematic behaviour of smoking, after identifying the commonalities and similarities, people seemed to enter the disputes detection process by making comparisons. As characteristically a participant indicates, the different stage and the different course of the participants helped them reflect on their own path, to make choices, to set goals. For other participants, this different stage of people, especially of those who had already achieved some of their goals, helped take courage, strength and hope $(n=2)$. Seeing people at a later stage contributed to believing that quitting smoking is eventually something realistic and to hoping that they themselves, with a similar effort, will be able 
to reach this stage. The role of hope is therapeutic in itself. It offers the group members the confidence to commit to the demanding team work and this motivates them to discover alternatives (Tudor, 1999). As mentioned by Yalom (1985) the establishment and maintenance of hope is essential to groups and makes members remain in groups. However, in order to change, hope is not enough. Participants must decide not only what to change but also how to change it. Therefore, they need to create an action plan, commit to it and use the tools offered by the group to find ways to accomplish it (Tudor, 1999).

\section{c) Function}

The group sessions in this study appeared to constitute a variety of different functions for each participant. As most of the group members stated, the process of group counselling helped them meet several people $(n=6)$ that were in the same process with them, and this made them feel that they are not alone $(n=1)$ in their endeavour. The good coordination of the consultant appears to have played an important role in the group functioning, as it was commented by a member of the group $(\mathrm{n}=1)$, but it was probably also important the fact that the group coordinator was not only the same in all group sessions, but also in all individual sessions of each team member. In this way it was ensured that the principles of motivational interviewing were also applied to the group. On the other hand, the consultant who knew the cases and particularly the specific resistances posed by the participants, could manage the team so that everyone had the opportunity to be heard and exchange views, to feel as an equal member of the team, something that as a participant noted, enhanced the acceptance and respect for all by all $(\mathrm{n}=1)$.

The main goal of motivational interviewing, which was used as a technique in individual sessions, is to increase the individual's faith to his own strength in order to overcome the obstacles and achieve the change. Noteably, the majority of the participants agreed that the main function of the groups were the support provided from the other group members $(n=5)$ that gave them strength and courage to continue, the members' cooperation $(n=7)$ which helped them to better understand certain aspects of their own efforts and to also learn about the techniques used by the other group members. This new information was a way out, an indication of a possible solution (quest) to address the problem of smoking behaviour, which they were still motivated to seek from the individual sessions. Seeing people who were at a more advanced stage to have achieved some of their goals, they raised hopes that they also may succeed and their self-efficacy was improved. Besides, in similar studies it has been shown that more than half of the respondents thought peer support as the main mean of the groups that helped them (Yalom, 2006). According to the literature, if the group provides support to its members in difficult issues that they are facing, then the dedication of the members will be very strong, but if the group fails to offer its members the help they are expecting, they will start showing less loyalty in it (Douglas, 2000).

d) Techniques

Regarding the techniques used during the group sessions, the participants said they 
were mostly helped by the discussion and identify it as the most important part of the whole counselling process. A key vehicle for the interaction and discussion among the team members is the self-disclosure, i.e. to share reactions on what is happening in the team, to reveal concerns, goals, dreams, joys and sorrows, strengths and weaknesses points. According to Shertzer and Stone (1981), self-disclosure is the feelings, attitudes and behaviours of the here and now. If team members are not willing to share themselves, it is very difficult for others to be able to look after them. The process of selfrevelation depends on the trust that the team members have toward one another (Bunch, Lund, \& Wiggins, 1983). According to what the participants said and was analysed above, this group seemed to have a very high consistency, while the composition of the group helped people to be tied as a team, be motivated and committed to achieve their goals. In such a cohesive group, the process of self-revelation was, according to the literature, expected (Kirschner et al., 1978).

The cohesion of the group, of course, was reinforced by the technique of commitment, which was typically used in individual sessions, following the motivational interviewing framework. This technique has been shown to strengthen the cohesion (Aiello, 1979), the universality (Brabender, 1985), while it also helps team members share their feelings with each other (Nystul, 1993). The majority of participants said that the group sessions were used as binding $(n=5)$. Their main thought was that they have been committed to so many people. The group functioned as a holding so as not to succumb to the temptations and as a reference point where they would apologise in case of relapse.

A very important element in the groups is that members can use each other to help themselves maintain their commitments (Tudor, 1999). Providing and receiving assistance was reported to be particularly helpful $(n=5)$ by most of the group participants. As discussed above, the group members exchanged knowledge and information, mainly in the form of advice. These tips constituted the technic of assistance which they were not only taking, but they were also giving to one each other. There was a typical expression of a member of the group I was charmed and satisfied by the idea that I can help and persuade other people to succeed, and also all participants reported, in the last evaluation meeting, that not only help from the other members seemed useful for them, but also that they were especially satisfied by realising that they were able to help, even a little, some of the other team members. The feeling that they may be important for others is a refreshing experience, which boosts their self-esteem. People also need to feel that they are important and useful (Yalom, 2006).

Of course, as recognized by most of the participants $(n=5)$, an important role in the effectiveness of providing and receiving assistance among group members seemed to have played their enhanced intrinsic motivation. The statement The fact that I was internally motivated was the basis on which all the rest were built is characteristic. Here, it appears that the technique of motivational interviewing in individual sessions was effective, as the intrinsic motivation of the participants, to which the particular technique was targeting, was increased and this contributed to more effective interaction between 
members and more effective information exchange. But also the structure-organization of group sessions was such that contributed to the good interaction among individuals. Most people perceived that they were actively involved in the group process, something that helped the group activities $(n=5)$. As revealed by question 2 (Table 3 ), the group activities were those that helped in exchanging information and reinforced thus the interaction among the group members. These activities also gave to the participants the opportunity to learn new tricks, understand how the others feel, give and receive advice, and as it seems, gave the participants the opportunity to provide and receive feedback.

The feedback from the other team members, increased their confidence when they felt they had not achieved some important steps, as mentioned by most of the participants $(n=5)$. Through feedback, the group members received information about the situation in which they were and also about all their effort up to the current point, through the eyes of the other members and they realised the effort they had put and the objectives they had achieved. This whole process was working as a driving force and helped the participants continue their effort, especially in cases they considered they hadn't made significant progress. According to the literature, the feedback is a multidimensional process as referred in the answers, the verbal messages and nonverbal behaviours of one against the other, and the group members must give feedback on how they have changed in the course of the group meetings (Gladding, 1996). The way that this group was operating, with strong coordination and exercises, was helpful in providing and receiving feedback.

The feedback exchange among the members of a team is widely considered as a key element in promoting learning through interaction (Morran, Stockton, \& Bond, 1991). The positive feedback of course, acts as reinforcement-rewarding of achievements, which as it was mentioned by the majority of the group, was of particular need, due to the difficult effort paid $(n=5)$. The fact that there were people who recognized their effort and strengthened them to go on, helped them continue and respectively reinforced, by themselves, the other team members. According to the literature (Tudor, 1999) the aid-support is a key intervention process within the groups.

\section{4) What were the difficulties during the group sessions?}

These questions were designed to identify what made it difficult for most of the participants in the process of group sessions so that to discern potential project difficulty and elements needed to watch and anticipate in any similar future intervention. As shown in Table 5, half of the participants said that there was nothing that made it difficult for them. In individual responses, however, there were some features, such as public engagement, the expectations of the other members and the successes of others, that at a first level made it difficult to some members, but later, as shown in the previous section, they were functioning in a positive manner.

The most important element that seemed to complicate the process of group sessions was the public commitment and personal defence manifested by some persons who apparently had exposure difficulties. The person who seemed to be particularly trou- 
Table 5. Results for the question which characteristics of the group sessions helped the participants?

\begin{tabular}{|c|c|}
\hline $2^{\text {nd }}$ order & Quotations \\
\hline Nothing $(\mathrm{n}=4)$ & $\begin{array}{l}\text { There is not anything that made it difficult for me in the process of group } \\
\text { sessions }\end{array}$ \\
\hline $\begin{array}{l}\text { The lack of common } \\
\text { experiences and similarities } \\
\qquad(\mathrm{n}=1)\end{array}$ & $\begin{array}{l}\text { That feeling that I do not have shared experiences, things, and generally } \\
\text { similarities in lifestyle with the rest of the team members, made it } \\
\text { particularly difficult for me. }\end{array}$ \\
\hline Personal defence $(\mathrm{n}=2)$ & $\begin{array}{l}\text { The small number of meetings resulted in some persons to develop a } \\
\text { defensive stance, which made it difficult for them to integrate and "be } \\
\text { exposed" to the group. I felt stagnant and that the discussion did not go } \\
\text { further when my mate in a role playing exercise showed several defences } \\
\text { and resistances. }\end{array}$ \\
\hline $\begin{array}{l}\text { The small number of } \\
\text { meetings }(n=1)\end{array}$ & $\begin{array}{l}\text { If the meetings were more frequent, we would have developed a different } \\
\text { kind of communication, even and outside the group (meetings), which } \\
\text { should help in team building. }\end{array}$ \\
\hline $\begin{array}{l}\text { The public commitment } \\
\qquad(\mathrm{n}=1)\end{array}$ & I did not like to feel tied in front of so many people. \\
\hline $\begin{array}{l}\text { The expectations of the } \\
\text { other members }(n=1)\end{array}$ & $\begin{array}{l}\text { Initially, I felt pressed and stressed that the other members had high } \\
\text { expectations of me. }\end{array}$ \\
\hline $\begin{array}{l}\text { The success of the others } \\
\qquad(\mathrm{n}=1)\end{array}$ & $\begin{array}{l}\text { I found excessive and disturbing some people's triumphalism about the } \\
\text { objectives they achieved. This whole process put me in agony and many } \\
\text { thoughts about how my path will evolve and whether I shall accomplish } \\
\text { my goals, something that was also tiring and stressful for me. }\end{array}$ \\
\hline $\begin{array}{l}\text { The discussion of other } \\
\text { issues }(\mathrm{n}=1)\end{array}$ & $\begin{array}{l}\text { I was tired sometime, when a team member was drifting and discussing } \\
\text { other personal issues. }\end{array}$ \\
\hline $\begin{array}{l}\text { The holding on public time } \\
\qquad(\mathrm{n}=1)\end{array}$ & It was difficult for me when some people abused the public time. \\
\hline
\end{tabular}

bled by the exposure process during the individual sessions said I suffer more when I keep on talking in front of others. All this does not let me get it over. Something that looked like would help him/her in this process was to know the team members in advance, so that to feel secure to begin the process of sharing thoughts and feelings and the self-revelation. He/she also said that the prevailing anguish often bothered him/her and he/she could not stand it. This personal defence, that came out mainly due to exposure difficulties could be overcome with more and frequent meetings, which would help in better group bonding, as it was also proposed by a group member. The small number of meetings is something that made it difficult for everyone and some people mentioned that in the final interview.

The expectations of some members from others seemed to initially make it difficult for some participants because they felt more committed, they had a higher load and had to work more to achieve their goal in order to repay the faith and trust to them. Along the way, of course, this was favourable in mobilizing them further during the quitting process in order to continue their effort to meet the others' expectations.

The success of the other members seemed to have a dual role analogous to expecta- 
tions. On one hand it was an extra difficulty by stressing some participants and making them worrying in achieving their own goals (Table 5) and on the other it seemed to motivate and make them hope that change is possible (Table 4).

Some other issues reported, had to do mainly with the operation of the Group, that is, some people abused the public time and brought to the discussion other topics besides smoking cessation. Using group time, while assuring being listened by the other members and also not dominating the discussion, is particularly important (Bion, 1959). Of course, learning to bring in balance between one's needs and the others' needs is a very useful process, but it takes time. So, this is yet another indication that more frequent meetings of the group is necessary. Of course, in the certain group, that type of issues was very limited, since as stated above (Table 4), the team coordination was very good and everyone had time to be listened.

\section{Conclusion}

The aim of this research was to investigate, whether group sessions are helpful and how, in a counselling intervention program for smoking cessation. The innovative part of the program was the combination of individual and group sessions and also the group per se, which included individuals that were at a different stage of behaviour change. Using the content analysis, it was studied how the specific techniques, characteristics and qualities of group sessions helped the participants, and also how group dynamics affected the above procedure.

As a main conclusion, we could say that the addition of group sessions was helpful because the group members were able to exchange and share ideas, experiences and emotions. The feeling that they are not alone and that there is a safe environment for them-the group-was particularly helpful. The different level of behaviour's change of the participants seemed to be helpful, because it gave them the opportunity to predict what might happen at some later stages, to make comparisons, preparing themselves for future situations and having thus no unanswered questions and gaps.

The technique of motivational interviewing used in individual sessions, seemed to have played an important role. Through this technique, the participants learned to look for solutions to their problems and be active listeners without criticizing. This contributed to a more efficient knowledge exchange among participants, mainly in the form of advice, and therefore to better interaction and group cohesion. Thus a safe environment was created, where members could freely express their feelings, offer and accepts help, especially in the form of feedback. Throughout this positive atmosphere, an important role was played by their high intrinsic motivation, which was the main goal of motivational interviewing and it was achieved during individual sessions.

An important limitation of the program seemed to be the small number of group sessions, and the long time intervals among them. All participants agreed that it would be preferable and more helpful if group meetings were more and more often held, once every 15 days, as it was suggested.

So far, no other investigations are known to study the effect of adding group sessions 
in individual counselling interventions for smoking cessation. It would be interesting to study the effectiveness of this combination in smoking cessation interventions in other populations too. Of course, the motivational interviewing appears to have a central role in the success of this research, although the effectiveness of other smoking cessation interventions is not well documented (Heckman, Egleston, \& Hofmann, 2010; Hettema \& Hendricks, 2010). The results of qualitative analysis combined with significant intervention success rate in this study may have important practical applications. It seemed that people at different behaviour change stages may compose a highly effective team, provided that they have the appropriate support in individual sessions.

\section{References}

Aiello, T. J. (1979). Short-Term Group Therapy of the Hospitalized Psychotic. Short-Term Approaches to Psychotherapy, 3, 101.

Bion, W. (1959). Experiences in Groups and Other Papers. New York: Basic Books.

Borgers, S. (1983). Uses and Effects of Modeling by the Therapist in Group Therapy. Journal for Specialists in Group Work, 8, 133-139. https:/doi.org/10.1080/01933928308411743

Brabender, V. (1985). Time-Limited Impatient Group Therapy: A Developmental Model. International Journal of Group Psychotherapy, 35, 373-390.

Bunch, B. J., Lund, N. L., \& Wiggins, F. K. (1983). Self-Disclosure and Perceived Closeness in the Development of Group Process. Journal for Specialists in Group Work, 8, 59-66. https:/doi.org/10.1080/01933928308411733

Camarelles, F., Asensio, A., Jimenez-Ruiz, C., Becerril, B., Rodero, D., \& Vidaller, O. (2002). Effectiveness of a Group Therapy Intervention to Quit Smoking. Randomized Clinical Trial. $\mathrm{Me}$ dicina Clinica, 119, 53-57. https:/doi.org/10.1016/S0025-7753(02)73312-5

Douglas, T. (2000). Survival in Groups. The Basics of Group Membership (3rd ed). Philadelphia: Open University Press.

Gladding, S. T. (1996). Counseling. A Comprehensive Profession (3rd ed.). Englewood Cliffs, New Jersey: Prentice-Hall.

Glassman, W. E. (1995). Approaches to Psychology (2nd ed.). Buckingham: Open University Press.

Goldstein, A., Heller, K., \& Sechrest, L. (1966). Psychotherapy and the Psychology of Behavior Change (Vol. 329). New York: Wilye.

Hassandra, M., Kofou, G., Zourbanos, N., Gratsani, S., Zisi, V., \& Theodorakis, Y. (2012). Initial Evaluation of a Smoking Cessation Program Incorporating Physical Activity Promotion to Greek Adults in Antismoking Clinics. Evaluation \& the Health Professions, 35, 323-330. https:/doi.org/10.1177/0163278712445202

Heckman, C. J., Egleston, B. L., \& Hofmann, M. T. (2010). Efficacy of Motivational Interviewing for Smoking Cessation: A Systematic Review and Meta-Analysis. Tobacco Control, 19, 410416. https:/doi.org/10.1136/tc.2009.033175

Hettema, J. E., \& Hendricks, P. S. (2010). Motivational Interviewing for Smoking Cessation: A Meta-Analytic Review. Journal of Consulting and Clinical Psychology, 78, 868-884. https:/doi.org/10.1037/a0021498

Huang, C. L. (2005). Evaluating the Program of a Smoking Cessation Support Group for Adult Smokers: A Longitudinal Pilot Study. Journal of Nursing Research, 13, 197-205.

https:/doi.org/10.1097/01.JNR.0000387541.83630.71 
Kirschner, R., Dies, R., \& Bron, R. (1978). Effects of Experimential Manipulation of Self-Disclosure on Group Cohesiveness. Journal of Consulting and Clinical Psychology, 46, 1171-1177. https:/doi.org/10.1037/0022-006X.46.6.1171

Mac Kenzie, K., \& Livesley, W. (1984). Developmental Stages: An Integrating Theory of Group Psychotherapy. Canadian Journal of Psychiatry, 29, 247-251.

Miller, W. R., \& Rollnick, S. (1991). Motivational Interviewing Preparing People to Change Addictive Behavior. New York: The Guilford Press.

Miller, W. R., \& Rollnick, S. (2002). Motivational Interviewing: Preparing People for Change (2 ed.). New York: The Guilford Press.

Moller, A. M., \& Tonnesen, H. (1999). Group Therapy and Smoking Cessation. Ugeskr Laeger, 161, 4987-4988.

Morran, D. K., Stockton, R., \& Bond, L. (1991). Delivery of Positive and Corrective Feedback in Counseling Groups. Journal of Counseling Psychology, 38, 410-414. https:/doi.org/10.1037/0022-0167.38.4.410

Nystul, M. S. (1993). The Art and Science of Counseling and Psychotherapy. Prentice-Hall.

Ramos, M., Ripoll, J., Estrades, T., Socias, I., Fe, A., Duro, R. et al. (2010). Effectiveness of Intensive Group and Individual Interventions for Smoking Cessation in Primary Health Care Settings: A Randomized Trial. BMC Public Health, 10. https:/doi.org/10.1186/1471-2458-10-89

Rasmussen, G., \& Zander, A. (1954). Group Membership and Self-Evaluation. Human Relations, 7, 239-251. https:/doi.org/10.1177/001872675400700208

Rollnick, S., \& Miller, W. R. (1995). What Is Motivational Interviewing? Behavioural and Cognitive Psychotherapy, 23, 325-334. https:/doi.org/10.1017/S135246580001643X

Shaw, M. E. (1974). An Overview of Small Group Behavior. University Programs Modular Studies, Morristown, NJ: General Learning Press.

Shertzer, B., \& Stone, S. C. (1981). Fundamentals of Guidance (4th ed.). Boston, MA: Houghton Mifflin.

Stead, L. F., \& Lancaster, T. (2005). Group Behaviour Therapy Programs for Smoking Cessation. Cochrane Database of Systematic Reviews, Article ID: CD001007. https:/doi.org/10.1002/14651858.CD001007.pub2

Tudor, K. (1999). Group Counseling. London: Sage.

Weiss, R. D., Jaffee, W. B., de Menil, V. P., \& Cogley, C. B. (2004). Group Therapy for Substance Use Disorders: What Do We Know? Harvard Rev Psychiatry, 12, 339-350. https:/doi.org/10.1080/10673220490905723

Winnicott, D. W. (1971). Playing and Reality. London: Penguin Books.

Woody, H. J. C., \& Rossberg, H. (1989). Counseling Psychology: Strategies and Services. Pacific Grove, CA: Brooks/Cole Publishing Company.

Yalom, I. D. (1985). The Theory and Practice of Group Psychotherapy (3rd ed.). New York: Basic Books. 
Submit or recommend next manuscript to SCIRP and we will provide best service for you:

Accepting pre-submission inquiries through Email, Facebook, LinkedIn, Twitter, etc. A wide selection of journals (inclusive of 9 subjects, more than 200 journals)

Providing 24-hour high-quality service

User-friendly online submission system

Fair and swift peer-review system

Efficient typesetting and proofreading procedure

Display of the result of downloads and visits, as well as the number of cited articles

Maximum dissemination of your research work

Submit your manuscript at: http://papersubmission.scirp.org/

Or contact psych@scirp.org 